\title{
ОСОБЛИВОСТІ ПЕРЕКЛАДУ АУДІОВІЗУАЛЬНОЇ ПРОДУКЦІЇ НА ПРИКЛАДІ ФІЛЬМУ ПІТЕРА ФАРРЕЛЛІ «ЗЕЛЕНА КНИГА»
}

\begin{abstract}
Анотація. Перехід від аналогового телебачення до цифрового, швидке зростання кіноіндустрії, Інтернету, глобалізація та легкий доступ до мультимедійних матеріалів е тими факторами, що сприяли успіху аудіовізуального перекладу. Сьогодні переклад сценаріїв кінофільмів викликаний гострою необхідністю ознайомити міжнародну аудиторію з певною аудіовізуальною продукцією. Локалізація мультимедіа, або іншими словами переклад відео, граффіки, анімації, GIF чи інфографіки е основою інтернаціонального розповсюдження аудіовізуальної продукції, а відтак припливу аудиторії, що своєю чергою призводить до стабільного фінансового зростання компаній-виробників. Однак, локалізація цього контенту може виявитися доволі складним завданням, оскільки контент повинен відповідати нормам та принципам місцевої культури. У статті зроблений короткий огляд методів перекладу аудіовізуальної продукції. Проведено аналіз українських субтитрів до кінострічки Пітера Фарреллі «Зелена книга» та виокремлено неточності у перекладі.
\end{abstract} Ключові слова: аудіовізуальна продукція, субтитрування, дубляж, локалізація, мультимедіа.

Shyika Yuliia, Horobets Olena Lviv Polytechnic National University

\section{FEATURES OF TRANSLATION OF AUDIOVISUAL PRODUCTS ON THE EXAMPLE OF PETER FARRELLY'S FILM "GREEN BOOK"}

Summary. The transition from analogue media technologies to digital, the rapid growth of the film industry, the widespread access to the Internet, globalization and the wide usage of multimedia are key factors that caused the critical need for audiovisual translation. Today, the translation of screenplays contributes to the popularization of audiovisual products among an international audience. Localization of multimedia, or in other words translation of video, graphics, animation, GIF or infographics, is the basis of international distribution of audiovisual products which helps to attract wide audiences, which in its turn results in the steady financial growth of film studios. However, localization of this content is challenging, as the content must comply with the norms and principles of local culture. A brief review of translation techniques applied to audiovisual products has been made and the advantages and disadvantages of subtitling and dubbing have been outlined. It was concluded that subtitling is the least time-consuming way to translate audiovisual products. Besides, subtitles do not distort the original text. As a result, subtitles provide full immersion in the language of the original product, its mood and culture. In the research different methods of translating audiovisual products have been described. A comparison of the original English script of Peter Farrelly's film "The Green Book" and Ukrainian subtitles has been made. As a result, several inaccuracies have been identified and divided into 5 categories: misprints, incorrect transliteration, lexical and technical inaccuracies and spelling errors. It has been concluded that the quality of Ukrainian subtitles for Peter Farrelly's film "The Green Book" is quite high, and the existing errors in the Ukrainian text could be avoided after qualified literary editing.

Keywords: Localization, dubbing, subtitles, audiovisual products, translation technics.

Постановка проблеми. Глобальне поширення 3МI та новітніх інформаційних технологій у сучасному суспільстві зумовили появу нових форм міжнародної та міжкультурної комунікації, що своєю чергою нерозривно пов'язані 3 появою нових форм перекладу. Кінематограф, як яскравий представник ЗМІ, став однією з найбільших поширених та впливових форм мистецтва. Глобалізаційні процеси загалом, та поширення аудіовізуальної продукції у глобальних масштабах зокрема, спричинило нагальну потребу якісного та короткотермінового перекладу кінострічок. Разом з тим, при перекладі аудіовізуальної продукції слід зважати на культурний та етносоціальний аспект цільової аудиторії.

Аналіз останніх досліджень і публікацій. Питання перекладу аудіовізуальної продукції, його особливостей та проблем було об'єктом дослідження як вітчизняних, так і зарубіжних науковці, зокрема Л. Богуцький, Е. Бруздзяк, Г. Денисова, П. Ореро, Л. Перез-Гонзалес, А. Ремель, Дж. Д. Сандерсон, та інші.
Виділення не вирішених раніше частин загальної проблеми. Актуальність дослідження зумовлена тим, що вперше було проведено аналіз англо-українського перекладу аудіовізуальної продукції на основі кінофрільму фільму «Зелена книга».

Мета статті. Стаття має на мені подати теоретичний огляд перекладу аудіовізуальної продукції та порівняти оригінальний англійський сценарій кінофільму «Зелена книга» 3 українськими субтитрами та виявити причини неточностей перекладу.

Виклад основного матеріалу. Для багатьох країн Європи, таких як Німеччина, Італія, Франція, Швеція та Нідерланди, перегляд дубльованих фольмів або фільмів із субтитрами $є$ нормою. Дубляж та субтитрування - це найпоширеніші форми перекладу аудіовізуальнї продукції, які дають змогу широкому загалу глядачів, які не володіють мовою кінопродукції, ознайомитись із закордонними стрічками, мультиплікацією тощо. Дубляя кінофрільму переважно означае, 
що візуальна складова, а інколи й фонові шуми та звуковий супровід, залишаються незмінними, тоді як текст, який проговорюють персонажі, перекладають на іншу мову та візуально адаптують до рухів та жестів акторів. Мета дубляжу полягає у створенні ілюзії, що різні персонажі насправді говорять цільовою мовою. На відміну від дубляжу, субтитри додаються як перекладений текст до оригінальної версії фрільму або серіалу (переважно у нижній частині екрану) і служать допоміжним мовним засобом, що дозволяе глядачам стежити за тим, що відбувається на екрані та розуміти аудіокомпоненту фільму чи серіалу [5].

Існуе два основних типи перекладу фрільмів дубляж та субтитрування, кожен з них по-своєму викривляє оригінальний текст. Термін дубляж переважно використовують для позначення методів перекладу аудіовізуальних продуктів 3 метою повного або часткового перекриття оригінального тексту текстом мовою цільової аудитоpii. 3 одного боку, дубляж, як відомо, є методом, який значною мірою модифікуе вихідний текст i таким чином ознайомлюе цільову аудиторію 3 аудіовізуальною продукцією шляхом локалізації. Це метод, при якому перекладений діалог налаштовуеться на рот і рухи актора у фрільмі, i його мета полягає у тому, аби змусити аудиторію відчути, що вони слухають акторів, які начебто говорять цільовою мовою. 3 іншого боку, субтитрування, тобто переклад розмовного діалогу з вихідної мови на цільову у вигляді синхронізованих підписів, найменше змінюе вихідний текст, однак не дозволяе цільовій аудиторії повністю зануритись у діалоги кінофрільму [9].

Як зазначає Ф. Шаме, дубляж - це тип аудіовізуального перекладу, який технічно полягає у заміні оригінальної доріжки діалогів фрільму (або будь-якого аудіовізуального тексту) на іншу доріжку, записану мовою цільової аудиторії. Решта треків залишаються незмінними [2]. Термін переозвучування інколи використовуеться як синонім дубляжу. Однак переозвучування також включає інтралінгвальну постсинхронізацію, тобто запис оригінальних діалогів фрільму у студії [1].

Проблема локалізації в перекладі є особливо актуальною у сфері сучасного кінематографру. Як зазначає Дж. Д. Сандерсон, переклад відбувається не між словами, а між культурами. Текст сприймається як невід'емна частина світу, а не як ізольований мовний уривок. Отже, процес перекладу розглядається як міжкультурний трансфрер, який визначається ступенем престижу вихідної і цільової культур, а також їх взаемними відносинами [8]. Як стверджуе Л. Роу, локалізація - це переклад у прозорому, вільному, «невидимому» стилі, яка використовуеться задля мінімізації «чужинності» оригінального тексту [6]. Дубльовані фрільми часто здаються глядачам, не перекладеними продуктами, а абсолютно новими кінострічками. Часто дубльований фільм перестае бути «чужоземним» і стає просто фрільмом. Таким чином, на міжнародному ринку оригінал фрільму фрункціонуе як транснаціональний декультурний продукт; він стає сировиною, яку слід повторно вписати в різні культурні контексти країн-споживачів за допомогою дубляжу.

Серед основних методів перекладу фрільмів субтитри передбачають найменше втручання в оригінал; іншими словами, це найбільш нейтральний, мінімально опосередкований метод. Саме субтитри сприяють відчуттю іноземної мови, настрою і зануренню в іншу культуру більше, ніж будь-який інший метод перекладу, адже переклад оригінальної звукової доріжки та діалогів не порушуеться, як при дубляжі. Окрім того, справжні голоси персонажів не лише полегшують розуміння діалогів, але й дають важливі підказки про статус, клас і взаємовідносини героїв [3]. Хоча довжина діалогів суттево скорочуеться через внутрішній характер субтитрів, більшість втраченого можна компенсувати, слухаючи оригінал чи за допомогою різноманітних невербальних засобів комунікації.

Як зазначає А. Ремель, субтитри можна означити як перекладацьку практику, яка полягає у поданні письмового тексту, як правило, в нижній частині екрану, який «намагаеться переказати» оригінальний діалог персонажів, а також дискурсивні елементи, що зображені на екрані (літери, вставки, графіті, написи, плакати тощо) та індрормацію, що міститься на саундтреках (пісні, голоси за кадром). У деяких мовах, наприклад японській, субтитри до кінопродукців подаються вертикально i, як правило, відображаються праворуч на екрані [7].

Усі кінопродукти, які містять субтитри, зазвичай складаються 3 трьох основних компонентів: вимовленого слова, зображення та субтитрів. Взаємодія цих трьох компонентів, здатність глядача читати як зображення, так і написаний текст 3 певною швидкістю, а також фрактичний розмір екрану визначають основні характеристики аудіовізуального продукту. Субтитри повинні відображатися синхронно із зображенням та діалогом, забезпечувати зрозумілість діалогу та залишатимуться на екрані досить довго, щоб глядачі могли їх прочитати [10].

Субтитри - це один з найкращих способів перекладу не лише з точки зору вартості, адже набагато дешевше задовольнити зростаючі потреби кіноринку, надаючи субтитри, які є більш дешевими та простішими у виробництві, але й тому, що для глядачів у країнах, які використовують субтитри, економічні переваги на другому місщі; на першому ж-збереження автентичності оригінального виробництва [4]. Для цих глядачів субтитри є більш автентичним методом перекладу, ніж дубляж.

Проте очевидним недоліком субтитрів є значне скорочення оригінального тексту, яке виникає в процесі перекладу. Підраховано, що при перекладі та створенні субтитрів, втрачається близько $20 \%$ оригінального тексту, а в деяких випадках i до 50\%. Часто перекладач не тільки перекладає 3 мови оригіналу на цільову мову, але й вирішує, які фррагменти опустити і які не несуть смислового навантаження для цільової аудиторії [1].

Проаналізувавши українські субтитри до орільму «Зелена книга», було виявлено 24 невідповідності, які можна класифікувати наступним чином:

- Одруківки;

- Неправильна транслітерація;

- Лексичні неточності;

- Ордоградрічні помилки;

- Технічні невідповідності. 
Під час аналізу українських субтитрів до кінострічки було виявлено 5 одруківок, які викликані людським фактором і не мають негативного впливу на загальне розуміння тексту, а саме: Ten to one, you slap this moolie out - Tecяmb do одного що ти ляснеш иього типа. Замість Tесять слід читати Деся ть); You have a very narrow assessment of me, Tony - У Вас звужені судження пролене, Тоні. $\mathrm{У}$ цьому прикладі можна побачити, що пропущений пробіл між словами про та мене; How could you not know this music? - Як Bu можене не знати ию музику? Замість можене слід читати можете, як і в наступному прикладі, You'd quite like her. Во трохи схожі з нею, замість Во слід читати $B u$.

Наступний клас невідповідностей це неправильна транслітерація, яку спричинило хибне розуміння правил перекладу власних назв. Виявлено 8 таких невідповідностей, а саме: $A s$ always, a very special thanks to Mr. Jules Podell for having us out - Як завжди особлива подяка містеру Жюлю Поделлу за те що він з нами. За правилами транслітерації слід перекладати ім'я Жюлю Поделлу як Джулсу Поделлу. Схожу неточність можна побачити у прикладі Hey, Gorman - Eü, Горлане. За правилами української транслітерації, англійська літера G повинна транслітеруватися як I, отож правильна транслітерація цього прізвища - це Горман. Kentucky, North Carolina, Tennessee, and on down through the Delta - Кентукі, Північна Кароліна, Теннесі $i$ аж до Дельти. У цьому прикладі пропущене подвоєння букви «с» в українському варіанті, тому Tennessee слід транслітерувати як Теннессі; схоже пропущене подвоєння букв у репліках We should really get going soon if we expect to get to Pittsburgh by dinner - Haм вapmo вирушати, якщо хочемо до вечора бути в Пітсбурзі до вечора та Chubby Checker - Чабі Чекер у словах Піттсбург та Чаббі відповідно. Aretha
Franklin - Apima Франк. Це ім’я слід транслітерувати як Арета Франклін згідно з правилами транслітераціiі. And can you see to it that there's a bottle of Cutty Sark - I простежте щоб в моему номері була пляшка Клаті Старк. Щодо цього прикладу, то вірогідно причиною такої транслітерації була неуважність перекладача або одруківка, тому правильна транслітерація бренду Cutty Sark буде Катmi Сарк.

Аналізуючи субтитри було виявлено 9 лексичних неточностей, а саме вживання русизмів, дослівного перекладу та калькування: It's good money - Це добрі гроші. У цьому прикладі використано неточний переклад, тому натомість краще вжити словосполуку хороший заробіток; Үои are so lucky - Tu такий везунчик. Слово везунчик - це русизм, тому його варто замінити на український еквівалент щасливчик; Like in the only way the word is ever used - В єдино моживому сенсі використання иього слова. У цьому прикладі ми бачимо одразу 2 помилки - це одрук і неточний переклад. Цю репліку варто б було перекласти $B$ єдиному значенні цього слова; "Tony the Lip" тау be a little... worldly for them - Тоні Ліп може видатися трохи... мирським для них. Слово мирський слід замінити на практичний або призеллений, адже слово мирський, як противага до секулярного, не підходить по контексту; It was a pleasure, Mr. Loscudo, really - Для мене ие задоволенн, містере Лоскудо. Цей приклад висвітлюе мінуси дослівного перекладу, оскільки переклад слова pleasure - задоволення, зовсім не вписуеться в контекст, а радше означає честь, тому і кінцевий переклад "для мене ие за честь..." мае логічний смисл у контексті; 48 White Castle burgers all in one sitting - Сорок вісіл бургерів "Білий Залок" за один присіст. Слово присіст це калька, яку слід замінити на прuсiд, або ж на за одним разом; So the boys in the kitchen whipped up a special menu - in honor of our guest - Хлопиі на кухні збили спеціальне меню в честь нашого гостя. Слово збили також не вписуеться в контекст і навіть вводить в оману глядачів і перешкоджае розумінню контексту. Отож правильний відповідник буде склали, чи більш розмовний варіант зляпали. Окрім того, згідно чинного правопису, в українській мові правильно говорити на честь, а не в честь; We need a Brillo Pad to wash these dishes with - Нали потрібна мочалка щоб полити посуд. У цьому прикладі ми також бачимо вживання русизму, а саме слова мочалка, яке слід замі00:09:16,430 ․> $00: 09: 18,890$ Досить, тату. Підлога була в плісняві

00:09:10,241 -> 00:09:11,941 The Copa's closing for repairs,

185

\section{1}

$00: 09: 11,943$-> $00: 09: 13,911$

so he just needs something

for a couple of months.

\section{6}

$00: 09: 22,153$-> $00: 09: 25,254$

All the people he knows, he' 11 find something in no time.

Рис. 1. Невідповідність оригінального тексту та субтитрів нити на українське слово губка; I'm gonna drink for two months - Пiдy в запой на два місяиі. Тут також використаний русизм запой, замість якого варто вжити українським відповідник заniü; It says right here, "Cozy as your own home." - Але пише, що тут Козі - ваш рідний діл. Ще один приклад дослівного перекладу, який кардинально змінюе суть і вводить глядача в оману. Правильний переклад фррази Cozy as your own home буде затишно, як дома. 
Також під час аналізу субтитрів, було виявлено 2 орфографічні помилки: I'll put 'em under the mattress - Я кластиму їх пid матрас. Оригінальне слово «mattress» слід писати як матраu. I'm eating potato chips - Я ̈̈м картопляні чіпси. Згідно з чинним правописом, в словах іншомовного походження після букви «ч» пишемо «и» (так зване «правило дев'ятки»), тому слово «сhips» має едине правильне написання чипси.

Інколи при створенні субтитрів виникають технічні збої, в результаті яких у тексті можуть виникнути деякі огріхи, такі як розсинхронізація субтитрів та екранного діалогу, опущення деяких реплік чи, навпаки, поява зайвих, як це показано на рисунку 1.

У цьому прикладі ми бачимо, що між двох оригінальних реплік, в українських субтитрах з'являються дві «зайві», які не вписуються ні у зміст, ні у смисл. Тому можна зробити висновок, що вони потрапили у текст через технічний збій.
Висновки і пропозиції. Разом зі стрімким розвитком та поширенням аудіовізуальної продукції виникла гостра іï доступності для широкого кола споживачів. Найменш трудозатратним способом перекладу такої продукції є субтитри, які передбачають найменше втручання в оригінальний текст. Тому саме субтитри сприяють відчуттю справжнього занурення у мову оригіналу, її настрій та культуру. Проаналізувавши українські субтитри до кінострічки Пітера Фареллі «Зелена книга», було виявлено кілька неточностей, які своєю чергою було поділено на 5 категорій: одруківки, хибна транслітерація, лексичні і технічні неточності та орфографічні помилки. Загалом можна зробити висновок, що якість субтитрів до вищезгаданої кінострічки е доволі високою, а наявних помилок в українському тексті можна було б позбутися після кваліфікованого літературного редагування.

\section{Список літератури:}

1. Bogucki L. Perspectives on Audiovisual Translation / L. Bogucki // Peter Lang, 2010. - 206 p.

2. Chaume F. Audiovisual Translation: Dubbing / F. Chaume // Routledge, 2020. - 208 p.

3. Cintas J.D. New Trends in Audiovisual Translation / J.D. Cintas // Multilingual Matters, 2009. - 216 p.

4. Cintas J.D. Voiceover and dubbing / J.D. Cintas, P. Orero // Amsterdam: John Benjamins, 2010. - 445 p.

5. Pinto S.R. Audiovisual Translation: Theoretical and methodological challenges / S.R. Pinto // John Benjamins Publishing Company, 2018. - 146 p.

6. Raw L. Translation, Adaptation and Transformation / L. Raw // A\&C Black, 2012. - 240 p.

7. Remael A. Audiovisual Translation: Subtitling / A. Remael, J.D. Cintas // Routledge, 2014. - 284 p.

8. Sanderson J.D. Focusing on Audiovisual Translation Research / J.D. Sanderson, C. Botella-Tejera // Universitat de València, 2019. - $240 \mathrm{p}$.

9. Szarkowska A. Forms of Address in Polish-English Subtitling / A. Szarkowska // Peter Lang, 2013. - 248 p.

10. Tveit J.E. Translating for Television: A Handbook in Screen Translation / J.E. Tveit // JK Publishing, 2005.

\section{References:}

1. Bogucki L. (2010) Perspectives on Audiovisual Translation. Peter Lang, 206 p.

2. Chaume F. (2020) Audiovisual Translation: Dubbing: Routledge, 208 p.

3. Cintas J.D. (2009) New Trends in Audiovisual Translation. Multilingual Matters, 216 p.

4. Cintas J.D. (2010) Voiceover and dubbing. Amsterdam: John Benjamins, 445 p.

5. Pinto S.R. (2018) Audiovisual Translation: Theoretical and methodological challenges. John Benjamins Publishing Company, $146 \mathrm{p}$.

6. Raw L. (2012) Translation, Adaptation and Transformation. A\&C Black, 240 p.

7. Remael A. (2014) Audiovisual Translation: Subtitling. Routledge, $284 \mathrm{p}$.

8. Sanderson J.D. (2019) Focusing on Audiovisual Translation Research. Universitat de València, 240 p.

9. Szarkowska A. (2013) Forms of Address in Polish-English Subtitling. Peter Lang, 248 p.

10. Tveit J.E. (2005) Translating for Television: A Handbook in Screen Translation. JK Publishing, 140 p. 